\title{
Obstacles Faced by Latina Mothers of Children with Autism
}

\author{
Emily D. Iland, Ivor Weiner, and Wendy W. Murawski \\ California State University, Northridge
}

\begin{abstract}
The CDC's most recent autism prevalence estimates document the continued trend of higher prevalence among non-Hispanic white children compared to Hispanic children. The disproportionate underrepresentation of Latino children in the health, education and service systems is measurable, disadvantaging the child and family. This quantitative study identifies support needs and obstacles experienced by 96 Latina mothers of children with autism, active in Spanish-language parent groups in California. Study measures included the Family Needs Survey and the Caring for My Child Survey. To determine the significance of the results on the Family Needs Survey, an item-by-item chi-square analysis compared results to those of to a similar population from a different study that used the same measure. A high proportion of mothers reported substantial levels of unmet needs in their role as primary caregiver using the Family Needs Survey: all 35 survey items were unmet for at least 50\% of mothers; 28 items were common needs. The level and number of unmet needs of mothers in the present study in areas such as social support and care services were significantly greater than the comparison group. On the Caring for My Child Survey, mothers identified multiple barriers personally encountered in obtaining assistance for their children including psychosocial, economic, political, and healthcare factors. Findings are relevant to improve access for Latinos in the health, education and service systems, and to establish a baseline for comparison.
\end{abstract}

(C) 2012 Californian Journal of Health Promotion. All rights reserved.

Keywords: special populations, Latinos, health disparities, autism, disproportional representation, Latina mothers

\section{Introduction}

Autism is a medical condition that affects the brain and central nervous system. Various neurological differences result in significant social, communication and behavioral deficits with pervasive effects on an individual's development, functioning and lifetime outcomes. Because the effects of autism range on a spectrum from mild to severe, the term Autism Spectrum Disorder, or ASD, is commonly used (National Research Council, 2001).

Autism is increasing in incidence in the United States. Statistics from the Centers for Disease Control indicate that one in 88 children now has an ASD, and that autism affects one in 54 boys (CDC, 2012). However, while autism affects people of all races, ethnicities, and socioeconomic groups, there is a significant disparity in the identification of Latino children with ASD. Current figures show that only 3.7-7.7 per 1,000 Hispanic children were identified as having an ASD, compared to 5.5-10.5 per 1,000 non-Hispanic white children.

Lower prevalence of autism in statistics does not represent less autism, but rather under-diagnosis of autism in the Latino population (CDC, 2012). For example, a study of children eligible for Medicaid found that on average, white children were identified at age six, after just four doctor visits. Latino children on average were not given an autism diagnosis until age seven, after more than eight doctor visits (Mandell, Listerud, Levy, \& Pinto-Martin, 2002). Adequate identification and diagnosis of Latino children with autism is particularly concerning given the rate of growth of the Latino population. Almost half, or $44 \%$, of the children in California from birth to age 17 are Latino (Children Now, 2007). 
Once diagnosed, the disparity continues in obtaining the necessary educational, behavioral, medical and social services for the child and family from various service systems. Latino children are under-represented in special education enrollment in the category of autism, not only disproportionately to their representation in the population, but also in comparison to children of other ethnicities (Dyches, Wilder, Sudweeks, Obiakor \& Algozzine, 2004). A Hispanic child has a risk ratio of 0.5 , or half the probability of being identified with autism, as compared to children of other racial/ethnic groups (United States Department of Education, 2004). Autism rates in Texas schools were two to three times higher among non-Hispanic whites compared to Hispanics (Palmer, Walker, Mandell, Bayles, \& Miller, 2010). In the California developmental service system, children born to poor, immigrant, non-English speaking, single, Latina mothers are least likely to receive state-funded services through the Regional Center system (Croen, Grether \& Selvin, 2002).

\section{Multiple Obstacles, Magnified Needs}

In studying Latino families of children with ASD, it is especially important to understand the central role of the mother as the primary caretaker, responsible for obtaining a diagnosis, becoming informed about the child's condition and needs, and accessing therapies and other support services (Bailey, Skinner, Rodriguez, Gut, \& Correa, 1999a). The literature depicts the general situation of Latina mothers as one of increased need and decreased access due to the interaction of multiple, complex factors (Maldonado-Durán, Munguía-Wellman, Lubin, \& Lartigue, 2000). It is likely that the disparity in diagnosis and the provision of services to Latino children with ASD can be explained by a combination of psychosocial, economic, political, and healthcare factors affecting their mothers (Iland, 2007; Magaña \& Smith, 2006).

As documented in the research literature, obstacles faced by Latina mothers include the language barrier (Fletcher \& Navarette, 2003), lack of information about autism, services, supports (Sanchez, 2006), provider barriers (Flores \& Vega, 1998), and lack of access to healthcare (Clark, 2002). The ability of Latina mothers to cope and adapt is also affected by socio-economic factors (Blacher \& McIntyre, 2006), immigration status and acculturation (Torres \& Rollock, 2004), political climate and policy (Fountain \& Bearman, 2011), discrimination (McHatton \& Correa, 2005), cultural factors (Gannotti, Handwerker, Groce, \& Cruz, 2001 Magaña \& Smith, 2006), and lack of social supports (Hancock, 2005).

Together, these inter-related factors can affect access to the diagnostic process and use of the healthcare, service and education systems, and hinder mothers' efforts to secure appropriate services for their children. Among Latina mothers, those who are monolingual, single, poor, newly-immigrated and/or of Mexican origin may have magnified needs (Marshall, Urrutia-Rojas, Soto Mas, \& Coggin, 2005). Such limitations may result in added stress to the mother and the family, and create additional risk for the child (Shieve, Blumberg, Rice, Visser \& Boyle, 2007).

\section{The Present Study}

To correct the inequities in the health, education and service systems and create access for Latino children with autism, it is essential to identify specific factors that contribute to their under- or delayed identification and determine what can be done to effect change (Sanchez, 2006). The two research questions of this study address a significant gap in the research. Research Question 1: What is the extent and nature of the support needs of Latina mothers of children with ASD in California compared to other Latina mothers of children with ASD? Research Question 2: What are the barriers that the mothers in the study have personally encountered in obtaining a diagnosis, services, and assistance for their children? This research provides data demonstrating the elevated needs of these mothers compared to a similar population, and identifies specific barriers they experienced. This information is relevant to efforts to meet the needs of Latina mothers more effectively, and to address barriers in the health, education and social service systems that are limiting access for Latino children with autism and their families. 


\section{Methods}

\section{Participants}

Participants in this research were 96 selfidentified Latina mothers of children with autism spectrum disorders (ASD) living in California who were active in one of three parent support organizations. These parent organizations assisted in identifying study participants. The majority of these mothers were married $(67.7 \%)$, between 30 and 45 years old (63.8\%), were born in Mexico (71.4\%), lived in the U.S. for more than ten years $(79.3 \%)$, had a high school education (59.3\%), and had between two and three children (69.1\%). Majority of the children with autism were of elementary school age $(58.7 \%)$, were boys $(83.9 \%)$, and were considered moderately to severely disabled $(83.0 \%)$. All of the children were receiving some level of services through the school district, regional center, or privately. Please see Tables 1 and 2.

\section{Procedures}

Study materials in English and Spanish were approved by the Committee for the Protection of Human Subjects at a large urban state university in southern California. All participants signed a Project Information Form, agreeing to participate. The questionnaire was anonymous; no identifying information was requested.

Leaders of four parent support organizations serving Latino families assisted the first author in identifying mothers willing to participate in the research. Questionnaires were supplied in person to three groups in the local area and administered by the first author. In addition, a large supply of study questionnaires in English and Spanish was mailed to the leader of a fourth parent group in northern California, who was instructed how to administer the questionnaire to ensure consistency.

Participants completed the questionnaire individually or in small groups at events sponsored by the parent organizations, such as the Encuesta de Necesidades Familiares (Bailey \& Simeonsson, 1988), was found to be appropriate for use with Latino populations (Bailey, Skinner, Correa, Arcia, Reyes-Blanes, support groups or conferences. Small group administration, in which the questions were read aloud and the participants filled in their individual responses, was an adaptation provided to accommodate different levels of literacy. Overall, questionnaires were completed over the course of three months.

The majority of questionnaires were returned in person, and one-quarter were returned by mail. Approximately 190 copies of the study questionnaires were distributed. A total of 96 questionnaires resulted in a response rate of approximately $50.5 \%$. The English form was selected by 13 participants (13.5\%), whereas 83 chose the Spanish form (86.5\%).

\section{Measures}

The study measures consisted of an anonymous questionnaire containing two surveys and demographic information. The Family Needs Survey (Bailey \& Simeonsson, 1988), a direct assessment, was used to determine the extent and nature of the support needs of Latina mothers of children with ASD. At the suggestion of the Family Needs Survey (FNS) authors, minor wording changes were made. The Latina mothers used the FNS to self-report their needs for 35 items in the areas of: Information $(n=7)$, Family and Social Support $(n=8)$, Financial $(n=6)$, Explaining to Others $(n=5)$, Child Care $(n=3), \quad$ Professional Support $(n=3)$, and Community Services $(n=3)$, areas "critical to family functioning" (Barnhart, Fitzpatrick, Sidell, Adams, \& Gomez, 1994). Examples of items include "information about my child's condition or disability," and "explaining my child's condition to other children." Participants could add other needs not listed.

The overall reliability and validity of the FNS were established in a study of 34 couples, with a high correlation between needs elicited between mothers and fathers ( $\mathrm{t}=-1.84, \mathrm{p}<.07$ ) (Bailey et al., 1999a). Test-retest reliability was moderate for mothers $(\mathrm{r}=.67)$ and high for fathers $(\mathrm{r}=$ $.81)$. The Spanish-language version of the FNS, the Encuesta de Necesidades Familiares (Bailey $\&$ Simeonsson, 1988), was found to be appropriate for use with Latino populations (Bailey, Skinner, Correa, Arcia, Reyes-Blanes, 
Table 1

Demographic Characteristics of Mothers

\begin{tabular}{|c|c|c|}
\hline Demographic Characteristics & $\underline{\mathrm{M}}$ & $\underline{\mathrm{SD}}$ \\
\hline Age & 38 & 8.1 \\
\hline Number of children & 2.8 & 1.8 \\
\hline Years of education & 12 & 4 \\
\hline Average income & $\$ 32,233$ & $\$ 23,550$ \\
\hline \multicolumn{3}{|c|}{ English Language Proficiency (ELP) } \\
\hline $\begin{array}{l}\text { Understand } \\
\text { English }\end{array}$ & 3.41 & 1.12 \\
\hline Speak English & 3.28 & 1.08 \\
\hline & $\mathrm{n}$ & $\%$ \\
\hline \multicolumn{3}{|l|}{ Country of Origin $(n=91)$} \\
\hline United States & 9 & 9.9 \\
\hline Mexico & 65 & 71.4 \\
\hline $\begin{array}{l}\text { Central } \\
\text { America }\end{array}$ & 11 & 12.1 \\
\hline & 6 & 6.6 \\
\hline \multicolumn{3}{|c|}{ Years in the United States $(n=92)$} \\
\hline Since birth & 8 & 8.7 \\
\hline $0-5$ & 4 & 4.4 \\
\hline $6-10$ & 23 & 25.0 \\
\hline $11-15$ & 21 & 22.8 \\
\hline $16-20$ & 18 & 19.6 \\
\hline More than 20 & 18 & 19.6 \\
\hline \multicolumn{3}{|l|}{ Marital status } \\
\hline Married & 65 & 67.7 \\
\hline $\begin{array}{l}\text { Unmarried } \\
\text { couple }\end{array}$ & 10 & 10.0 \\
\hline $\begin{array}{l}\text { Single (not } \\
\text { married, } \\
\text { divorced, } \\
\text { separated, } \\
\text { widowed) }\end{array}$ & 20 & 20.8 \\
\hline No response & 1 & 1.0 \\
\hline \multicolumn{3}{|l|}{ Primary/preferred language } \\
\hline English & 13 & 13.5 \\
\hline Spanish & 83 & 86.5 \\
\hline
\end{tabular}

Rodriguez, \& Vazquez-Montilla, 1999b). Multiple researchers have used the FNS to study different parent populations whose children had a variety of disabilities (Reyes-Blanes, Correa, \& Bailey, 1999).
The Caring for My Child Survey (Iland, 2007) was specially designed for this research to identify obstacles or barriers that Latina mothers had personally encountered in their efforts to help their children. The 22 items in the Caring for My Child Survey (CMCS) were selected from an extensive literature review of the obstacles faced by primary caregivers of children with disabilities in meeting family needs in two phases of care (1) obtaining a diagnosis, and (2) parenting the child, including securing educational programs, therapies and supports. Participants were asked to respond "Yes" or "No" to indicate whether a stated item had affected the treatment of their child. Examples included, "A doctor or medical professional told me that there was nothing wrong" and, "The paperwork in clinics was complicated."

Several items in the CMCS represented sociocultural features unique to Latino families as described in the literature. For example, the item, "Family members or elders thought there was no problem," was based on Latino cultural values related to family consensus in decision making and help-seeking (Clark, 2002). The item "I was fearful of problems with immigration status if I asked for help for my child" addressed the potential impact of this socio-political factor (Fountain \& Bearman, 2011).

The CMCS survey had not been used previously on a large-scale study. Though reliability and validity data was not obtained for the $C M C S$, the reliance on a strong research literature base provides content validity. The survey was designed in English and translated into Spanish by the first author, then edited by a native speaker. Participants could add comments regarding any other factor impacting the care of their child.

Demographic information about the mothers and children was included at the end of the questionnaire. Background questions included the mother's marital status, level of education, income, and country of origin. Information about the child included age, the amount of time 
Table 2

Demographic Characteristics of the Child with Autism

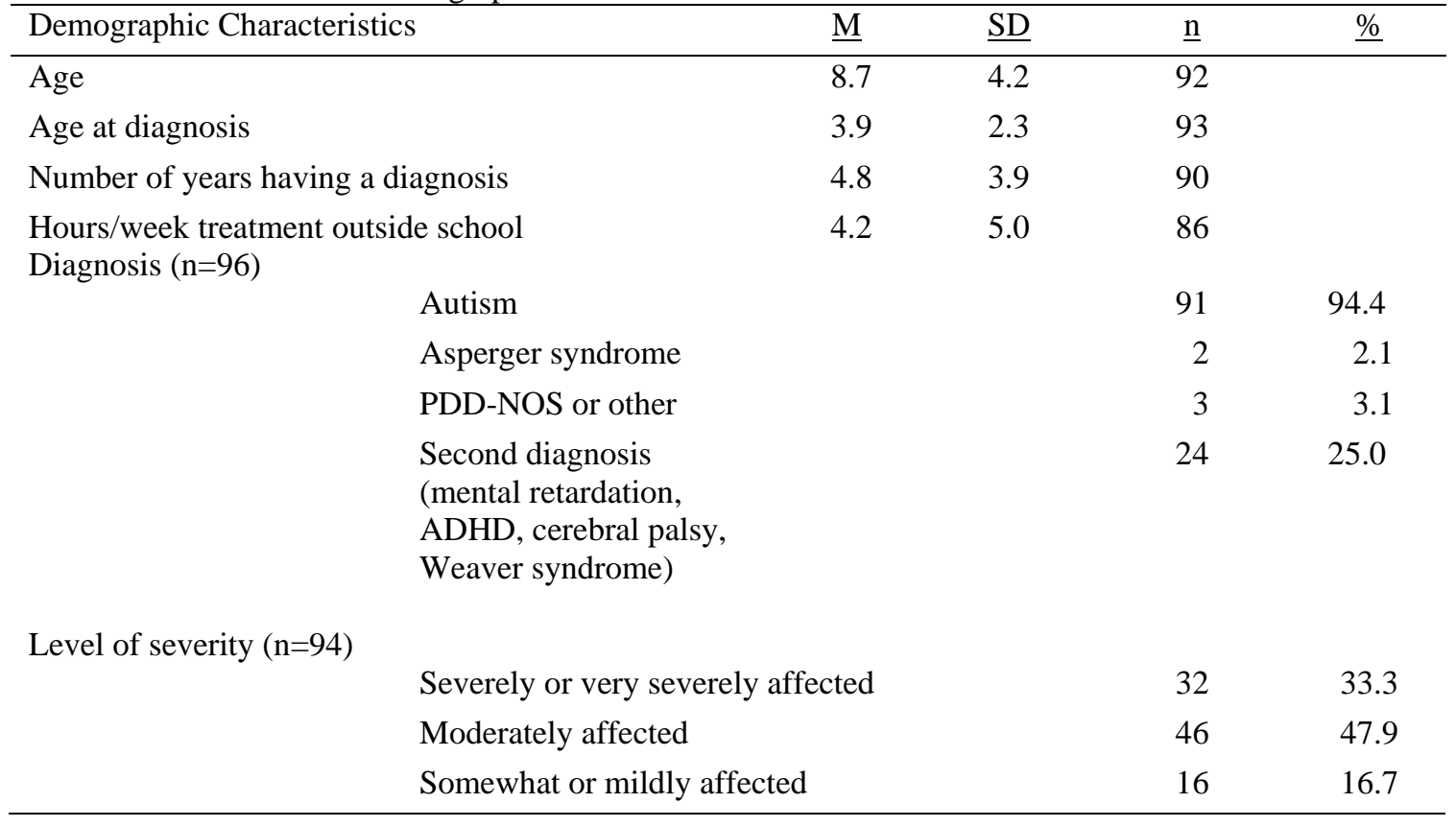

the child had been diagnosed, and the child's eligibility for educational and support services.

\section{Analysis}

Initial descriptive analyses, compared the demographic characteristics of the present sample of California mothers (reported earlier in Table 1) with the characteristics of mothers in the Sanchez (2006) sample, which was drawn from a large Midwestern city. Next, the main analyses compared the needs stated by the present sample with those expressed by parents in the Sanchez (2006) sample. Specifically, for each item in the Family Needs Study instrument, we conducted a separate chi-square analysis to determine whether the distribution of responses in the present sample differed significantly from the distribution of responses to the item in the Sanchez (2006) sample. The final stage in the analysis reported descriptive statistics from the Caring for My Child Survey. Because the Caring for My Child Survey is a new instrument, which has not been used in previous studies, it was not possible to compare responses from the present sample with those found in other samples.

\section{Results}

Demographic characteristics of the California mothers in this study were quite similar to the comparison group (Sanchez, 2006) in areas such as mean age $(38 \pm 8.1)$, years in the U.S. $(17.7 \pm 10.3$ vs. 13.9) and years of education $(12 \pm 3.9$ vs. 14$)$. The mean age of the children with autism $(8.7 \pm 4.3$ vs. 10.3$)$ and age at diagnosis ( $3.9 \pm 2.3$ vs. 3.8$)$ were similar as well. In the FNS, an item was considered a "need" if $50 \%$ of the respondents endorsed it; an item was considered a "common need" if endorsed by $70 \%$ of respondents (Bailey et al., 1999b).

\section{The Family Needs Survey}

Results showed a high proportion of the 96 Latina mothers in the present study had a significant number of unmet needs. In fact, the mothers reported all 35 of the total items as "needs," and 29 of 35 items were reported as "common needs." A definite need for help was reported on the average item by $77.4 \%$ of respondents. The greatest needs expressed were in the area of Information, with $75 \%$ to $91 \%$ of participants endorsing all seven items.

In the area of Family and Social Support, all seven items were endorsed by $72 \%$ to $87 \%$ of participants. In the Financial scale, all six needs 
Table 3

"Yes" Responses to Family Needs Survey

\begin{tabular}{|c|c|c|c|c|}
\hline & \multicolumn{2}{|c|}{$\begin{array}{l}\text { Present Study } \\
\quad(n=96)\end{array}$} & \multirow{2}{*}{$\begin{array}{c}\begin{array}{c}\text { Sanchez Study } \\
(\mathrm{n}=31)\end{array} \\
\% \text { yes } \\
\end{array}$} & \multirow[b]{2}{*}{$\chi^{2}$} \\
\hline & $\mathrm{f}$ & $\%$ yes & & \\
\hline \multicolumn{5}{|l|}{ Information } \\
\hline 1. How children grow and develop & 72 & 75.6 & 93.5 & 3.29 \\
\hline 2. How to play with or talk to my child & 79 & 86.3 & 96.8 & 1.09 \\
\hline 3. How to teach my child & 87 & 90.6 & 93.5 & 0.09 \\
\hline 4. How to handle my child's behavior & 85 & 91.5 & 80.6 & 1.42 \\
\hline 5. My child's condition or disability & 79 & 87.3 & 87.1 & 0.00 \\
\hline 6. Services that are presently available to my child & 83 & 90.1 & 80.6 & 1.07 \\
\hline 7. Services my child might receive in the future & 83 & 89 & 96.8 & 0.60 \\
\hline \multicolumn{5}{|l|}{ Family \& Social Support } \\
\hline 8. Talk with someone in my family about concerns & 63 & 72.5 & 58.1 & 3.43 \\
\hline 9. Have friends that I can talk to & 70 & 78.6 & 51.6 & 13.56 \\
\hline 10. Find more time for myself & 78 & 83.1 & 71.0 & 1.98 \\
\hline 11. Help my spouse accept the child's condition & 66 & 72.4 & 38.7 & 28.17 \\
\hline 12. Help my family discuss problems and reach solutions & 75 & 82.8 & 67.7 & 3.23 \\
\hline 13. Help my family support each other difficult times & 79 & 87.4 & 61.3 & 10.67 \\
\hline 14. Decide who will do household chores, childcare, tasks & 60 & 72.2 & 32.3 & 47.32 \\
\hline 15. Decide on and doing family recreational activities & 72 & 81.2 & 48.4 & 21.34 \\
\hline \multicolumn{5}{|l|}{ Financial } \\
\hline 16. Paying for expenses such as food, housing, medical care, & 66 & 69.9 & 54.8 & $3.99^{1}$ \\
\hline 17. Getting special equipment for my child's needs & 69 & 75.3 & 38.7 & 33.23 \\
\hline 18. Paying for therapy, day care, or other services my child needs & 74 & 77.4 & 58.1 & $6.15^{1}$ \\
\hline 19. Counseling or help in getting a job & 57 & 59.3 & 41.9 & $6.94^{2}$ \\
\hline 20. Paying for babysitting or respite care & 75 & 77.6 & 41.9 & 29.20 \\
\hline 21. Paying for toys that my child needs & 62 & 62.4 & 35.5 & 19.57 \\
\hline \multicolumn{5}{|l|}{ Explaining to Others } \\
\hline 22. To either my parents or my spouse's parents & 62 & 67 & 41.9 & 14.43 \\
\hline 23. To my child's siblings & 63 & 74.4 & 25.8 & 87.89 \\
\hline 24. To friends, neighbors or strangers & 68 & 77 & 45.2 & 21.48 \\
\hline 25. To other children & 80 & 84.1 & $\mathrm{n} / \mathrm{a}$ & \\
\hline \multirow{2}{*}{ 26. Finding reading material about other families like mine } & 76 & 79.5 & 77.4 & 0.05 \\
\hline & $\mathrm{f}$ & $\%$ yes & $\%$ yes & $\chi^{2}$ \\
\hline \multicolumn{5}{|l|}{ Child Care } \\
\hline 27. Babysitters or respite care providers & 82 & 82.4 & 45.2 & 29.39 \\
\hline 28. A day care center (or preschool) & 57 & 59 & 51.6 & 1.02 \\
\hline \multirow[t]{2}{*}{ 29. Child care during church or services } & 59 & 70.7 & 19.4 & 130.2 \\
\hline & $\mathrm{f}$ & $\%$ yes & $\%$ yes & $\chi^{2}$ \\
\hline \multicolumn{5}{|l|}{ Professional Support } \\
\hline 30. Meeting with a priest/minister or religious leader & 35 & 50 & 19.4 & 46.34 \\
\hline 31. Meeting with a counselor (psychologist, social worker, etc). & 63 & 82.4 & & \\
\hline 32. More time to talk to my child's teacher or therapist & 68 & 79.8 & 41.9 & 32.91 \\
\hline \multicolumn{5}{|l|}{ Community Services } \\
\hline 33. Meeting \& talking with other parents of handicapped children & 85 & 85.2 & 96.8 & 1.33 \\
\hline 34. A doctor who understands me and my child's needs & 79 & 81 & 19.4 & 187.7 \\
\hline 35. A dentist who will see my child & 75 & 74.4 & 35.5 & 40.92 \\
\hline
\end{tabular}

Note: Not all mothers responded to every item. Percentage for each item is based on the number of "yes" responses divided by the total number of responses to that item.

Critical value of $\chi^{2}$ for ${ }^{1} \mathrm{p}<.05=3.84,{ }^{2} \mathrm{p}<.01=6.64,{ }^{3} \mathrm{p}<.001=10.83$ 
were endorsed by $62 \%$ to $77 \%$ of participants. All five items in the Explaining to Others scale were endorsed by $67 \%$ to $84 \%$ of participants; the greatest need was seen in explaining the child's condition to other children. Similar levels of need were reported in the areas of Childcare, Professional Support and Community Services. Refer to Table 3 for all results of this study.

\section{Comparison to Latino Parents in a Non- Californian Sample}

Results supported the assertion the mothers in this research have a magnified number of unmet needs compared to a similar population in Sanchez's (2006) study, as shown in Table 3. While parents in Sanchez's study reported 17 of the 35 items as needs (endorsed by $50 \%$ or more of the respondents), mothers in the current study reported all 35 items as needs, representing a $105.9 \%$ greater level of needs. While parents in Sanchez's study reported 10 items as common needs (endorsed by $70 \%$ or more of the respondents), mothers in the current study Caring for My Child Survey

Of the 22 survey items, 11 barriers were reported by at least $50 \%$ of participants as having impacted the care of their child. Four barriers were experienced by $70 \%$ or more of participants and can be considered common barriers, which were: difficulty understanding how the special education or school system works (86\%); understanding how the medical and social service systems work (84\%); complicated paperwork (79.3\%); and finding a medical or other professional to make the diagnosis $(70.8 \%)$. A high percentage of respondents identified additional barriers, including being told that there was nothing wrong with the child by family members (69.2\%) and by medical professionals (68.5\%), difficulty with reading or writing English $(61.5 \%)$, and difficulty speaking or understanding English (57.6\%). Table 4 depicts all results related to the Caring for My Child Survey.

\section{Discussion}

Taken together, the measures in this research indicate that the majority of Latina mothers of children with ASD in the study reported a significantly high level of support needs and reported 29 items as "common needs" representing a $290 \%$ greater level of common needs.

An item-by-item chi-square analysis revealed a pervasive pattern of greater need in the present study relative to Sanchez's sample. As shown in Table 3, a magnified need for information was shared by both groups. Significant differences between samples were found on five of the eight family and social support items, all six of the financial need items, two of the three items related to explaining the condition to others, two of the three childcare items, both professional support items, and two of the three community services items. When significant differences between samples were found, a larger proportion of the California sample indicated that they had unmet needs. Two of the most significant item comparisons of the mothers in this study were the need for "a doctor who understands me and my child's needs," and the need for childcare during religious or church services. multiple obstacles affecting their ability to care for their special needs children. The magnitude of needs was significantly greater than that of a similar population studied using the same measure (Sanchez, 2006). The mothers in this study personally experienced multiple barriers in obtaining and using services, some of which may be closely linked to cultural differences, socio-economic factors, and the political context of California that may affect access to healthcare (Fountain \& Bearman, 2011). This situation has clear implications for consequent stress, vulnerability and disadvantages for mothers in their role as primary caregiver, and for additional risk to the child with autism.

\section{Substantial Needs}

The unique and complex features of autism may heighten the mothers' need for information. The need for information to manage the child's behavior was the highest rated item in the FNS, with $91.5 \%$ of mothers indicating this need. This is consistent with Sanchez's study (2006), and with the literature that suggests that Latina mothers feel pressure to control their child's behavior and are judged by others within and outside of the family when they cannot do so (Maldonado-Durán et al., 2000). Information 
about behaviors may also have been rated high due to the daily stress caused by problem behaviors, and the significant amount of information and support needed to improve behaviors.

Information about how to talk and play with the child (communication and socialization) was a need reported by $86.3 \%$ of mothers.
This is understandable because talking and playing are a part of daily interactions with children, and may be particular challenges for mothers of children with ASD. This situation may be somewhat more complicated for the monolingual mothers in this study whose children receive therapy and instruction in English, or for mothers who do not have access to information in Spanish on these topics.

\section{Table 4}

Yes Responses to Caring for My Child Survey ( $\mathrm{n}=96$ )

\begin{tabular}{lcc}
\hline Do You Think Your Child Was Impacted by Any of the Following? & \# yes & $\%$ yes \\
\hline 1. It was difficult to understand how special education or school systems & 80 & 86.0 \\
work. & 79 & 84.0 \\
2. It was difficult to understand how the medical and social service & 69 & 79.3 \\
systems work. & 63 & 70.8 \\
3. The paperwork at clinics, schools or agencies was complicated. & 63 & 69.2 \\
4. It was hard to find a professional to make a diagnosis. & 61 & 68.5 \\
5. Family members/elders thought there was no problem. & 56 & 61.5 \\
6. A doctor or medical professional told me that there was nothing wrong. & 53 & 60.9 \\
7. It is difficult to read or write English. & 54 & 59.3 \\
8. I did not know who to call or where to go for help. & 53 & 57.6 \\
9. I had difficulty getting childcare for my other children so I could take & \\
my child with autism to appointments or services. & 46 & 52.3 \\
10. It is difficult to speak or understand English. & 43 & 48.9 \\
11. A doctor or medical professional gave my child a different diagnosis \\
than autism. \\
12. Professionals were not courteous or did not listen to my concerns. \\
13. I did not realize anything was wrong for some time. & 41 & 44.6 \\
14. I did not have enough time in my schedule. & 40 & 44.4 \\
15. I had difficulty with transportation, getting to doctors or services & 38 & 41.8 \\
16. The cost of medical care was too high. & 37 & 41.1 \\
17. I did not know the signs of autism. & 37 & 40.2 \\
18. I faced discrimination from professionals or providers because I am & 31 & 35.2 \\
Latina. & & \\
19. Teachers or staff at school thought my child's problems were caused & 29 & 33.0 \\
by being an English Language Learner or because Spanish was spoken at \\
home.
\end{tabular}

The majority of mothers in this study also indicated substantial levels of unmet needs in all other scales of the FNS: Family and Social Support, Financial, Explaining to Others,
Childcare, Professional Support, and Community Services. These multiple unmet needs, affecting every aspect of daily life, present a clear picture of the inter-related 
difficulties these mothers may face, which are clearly elevated in number and magnitude, compared to a similar group of parents living in the Midwest (Sanchez, 2006).

The complex, multiple needs of a child with autism may also increase the mother's need to actively advocate to have those needs met. This theme is reflected in the needs added by 77 mothers to the FNS, regarding how to access services, the need for help to do so, and the need for access to quality services. These challenges may be particularly difficult for Latino mothers who have difficulty expressing their needs, either due to a language barrier or the cultural norm of not questioning those in authority (McHatton \& Correa, 2005).

\section{Barriers Reported}

The high level of unmet needs reported in all scales of the Family Needs Survey implies that there are barriers preventing Latina mothers in California from having their needs met. This study confirms the hypothesis that many Latina mothers of children with ASD have commonly experienced multiple barriers in access to care. Multiple barriers were experienced at the initial stage of diagnosis, and after a diagnosis was obtained.

This research confirms the obstacles in accessing services reported in the literature, including complex, inter-related factors such as a language barrier, lack of information about autism, limited access to quality services, lack of access to health care, socio-economic factors, immigration status, acculturation issues, discrimination, cultural factors, and lack of social supports. The results are particularly concerning considering that the mothers in this study had lived in the U.S for a significant period of time and were not recently immigrated (mean $=17.68$ years).

\section{Prescriptive Implications and} Recommendations

The effects of autism are pervasive for the child and family, generating multiple issues, whether the person with ASD is affected mildly, moderately or severely. The identification of numerous unmet needs and specific barriers experienced by the participants in this study gives direction to the areas and extent of help needed by Latina mothers of children with ASD in California. Children with ASD and their families require the attention and resources of the medical community, educational agencies and service systems. This is especially true in light of the statistically significant number of unmet needs of mothers in the present study in areas such as social support, care services, and financial, which far exceed those of the comparison group of Midwestern parents.

This is the time for the California health and service systems to respond to the significant needs of parents and children with autism and to reduce the documented disparity between populations. There is a clear need for information about autism in Spanish to raise awareness about autism in the Latino community. Shared knowledge may improve consensus within families and promote active help-seeking behaviors. Latino families also need access to qualified medical and service providers who speak Spanish and have expertise in autism.

Based on sheer numbers, healthcare providers may improve the situation by conducting the recommended developmental screening at the 18 and 24 month well-child visits using the MCHAT (Modified Checklist for Autism in Toddlers) or a similar tool (American Academy of Pediatrics, Committee on Children with Disabilities, 2001). Screening can help with the diagnostic and referral process and give more Latino children access to early intervention services. Having Spanish speaking persons collect the child's full history, capture parental concerns, and use checklists of development in Spanish could help parents report relevant information. Efforts may be promoted in clinics to limit the number of doctors who follow the child so that development is tracked and developmental concerns over time are recognized.

\section{Strengths and Limitations of the Study}

This is one of few existing studies with an adequate sample size focusing on Latinos and autism, and in particular, the needs of mothers. 
Few previous studies have focused on Latina perceptions of having experienced specific barriers (Flores \& Vega, 1998). A strength of this study is the clear identification of needs and priorities that can lead to improved healthcare and community services for families. The research participants reflected characteristics of the general Latino population in California with respect to language proficiency, level of education, mean income, age, and length of time in the U.S. Participants from a variety of countries of origin were included, with the proportional majority being of Mexican origin. Central and South American countries of origin were over-represented, and Cuban and Puerto Rican origins were under-represented. The research considered the Latino population as a whole and was not intended to make comparisons among subgroups.

The generalization of findings from this study is limited by the fact that the participants were not randomly selected. The research sample was limited geographically to California and did not include Latinos living in other parts of the country. Participation was voluntary. The results may be also affected by the fact that the children of all participants had a confirmed diagnosis and that most participants were part of a parent support organization; this means that the needs of parents in the process of identification and diagnosis or those who are at the beginning stages of symptom recognition were not included in the sample group.

This research included a survey instrument designed for this study based on the literature on barriers. While the psychometric properties of the Caring for My Child Survey have not been statistically analyzed, the items in the survey appeared to resonate with parents based on their comments, which were consistent with the participants' responses elsewhere in the questionnaire. Perceptions of weighting due to phrasing or response options may be considered a limitation.

\section{Future Research}

Conducting a larger study that includes a random, representative, geographically diverse sample would be helpful to determine how widespread the needs of Latino families of children with ASD are. Such a study would also help to determine whether Latinos living in different parts of the nation and different Latino subgroups experience the same or different level of needs and barriers in the help-seeking process as the participants in this study. Future plans for on-going research should include the use of the Family Needs Survey with non-Latino parents of children with ASD for purposes of comparison. Studies to determine the psychometric properties of the Caring for My Child Survey would validate the use of this instrument with Latino populations and determine its utility for other parent populations.

\section{Conclusion}

With the incidence of autism on the rise and the continued growth of the Latino population, the needs of the Latino population with ASD will continue to grow in California. This study provides preliminary evidence about the substantial level of unmet support needs, and significant obstacles faced by Latina mothers in their efforts to order to obtain a diagnosis, advocate for their children, and cope with the daily demands of care. Many Latina mothers of children with autism face multiple disadvantages and have magnified needs that may be exacerbated by the cultural factors, socioeconomic factors and the political climate in California. Identification of the barriers, obstacles, and needs, such as those shared by the Latina mothers in this study, can help healthcare, educational and service professionals work with parents, advocates and legislators to improve the quality of care for this population. Access to healthcare and culturally competent providers, equitable policies, quality programs, and the collective efforts of everyone involved are keys to redressing inadequacies and give Latino children with autism a fair chance in life. 


\section{References}

American Academy of Pediatrics, Committee on Children with Disabilities. (2001). Technical report: The pediatrician's role in the diagnosis and management of autistic spectrum disorder in children. Pediatrics, 107(5), 85-102.

Bailey, D.B. Jr., \& Simeonsson, R.J. (1988). Assessing the needs of families with handicapped infants. The Journal of Special Education, 22(1), 117-127.

Bailey, D.B. Jr., Skinner, D., Rodriguez, P., Gut, D., \& Correa, V. (1999a). Awareness, use, and satisfaction with services for Latino parents of young children with disabilities. Exceptional Children, 65(3), 367-381.

Bailey, D.B. Jr., Skinner, D., Correa, V.I., Arcia, E., Reyes-Blanes, M.E., Rodriguez, P., VazquezMontilla, E. (1999b). Needs and supports reported by Latino families of young children with developmental disabilities. American Journal on Mental Retardation, (104)5, 437-451.

Barnhart, L.L., Fitzpatrick, V.D., Sidell, N.L., Adams, M.J., \& Gomez, S.J. (1994). Perception of family need in pediatric oncology. Child and Adolescent Social Work Journal, 11(2), 134-148.

Blacher, J., \& McIntyre, L.L. (2006). Syndrome specificity and behavioral disorders in young adults with intellectual disability: Cultural differences in family impact. Journal of Intellectual Disability Research, 50(3), 184-198.

Centers for Disease Control and Prevention. (2012). Prevalence of autism spectrum disorders: Autism and developmental disabilities monitoring network, 14 sites, United States, 2008. Morbidity and Mortality Weekly Report 61, 1-19. Retrieved June 11, 2012 from http://www.cdc.gov/mmwr/preview/mmwrhtml/ss6103a1.htm?s_cid=ss6103a1_w

Centers for Disease Control. (2009). Prevalence of autism spectrum disorders: Autism and developmental disabilities monitoring network, United States, 2006. Morbidity and Mortality Weekly Report, 58, 1-20. Retrieved May 20, 2010, from http://www.cdc.gov/mmwr/preview/mmwrhtml/ss5810a1.htm

Children Now. (2007). The unique challenges to the well-being of California's border kids. Retrieved July 21, 2007 from http://publications.childrennow.org/assets/pdf/policy/borderkidscount2007.pdf

Clark, L. (2002). Mexican-origin mothers' experience using children's healthcare services. Western Journal of Nursing Research, 24(2), 156-179.

Croen, L.A., Grether, J.K, \& Selvin, S. (2002). Descriptive epidemiology of autism in California: Who is at risk? Journal of Autism and Developmental Disorders, 32(3), 217-224.

Dyches, T.T., Wilder, L.K., Sudweeks, R.R., Obiakor, F.E., \& Algozzine, B. (2004). Multicultural issues in autism. Journal of Autism and Developmental Disorders, 34(2), 211-222.

Fletcher, T.V., \& Navarette, L.A. (2003). Learning disabilities or difference: A critical look at issues associated with the misidentification and placement of Hispanic students in special education programs. Rural Special Education Quarterly, 22(4), 37-46.

Flores, G., \& Vega, L.R. (1998). Barriers to health care access for Latino children: A review. Family Medicine, 30(3), 196-205.

Fountain, C., \& Bearman, P. (2011). Risk as social context: Immigration policy and autism in California. Sociological Forum, 26(2), 215-240.

Gannotti, M.E., Handwerker, P.W., Groce, N.E., \& Cruz, C. (2001). Sociocultural influences on disability status in Puerto Rican children. Physical Therapy, 81(9), 1512-1523.

Hancock, T.U. (2005). Cultural competence in the assessment of poor Mexican families in the rural southeastern United States. Child Welfare, 84(5), 689-711.

Iland, E.D. (2007). Half a chance is not enough: Latina mothers of children with autism struggle for equity. Unpublished master's thesis, California State University, Northridge. Dept of Special Education. 
Maldonado-Durán J.M., Munguía-Wellman, M., Lubin, S., \& Lartigue, T. (2000). Latino families in the perinatal period: Cultural issues in dealing with the healthcare system. Retreived February 12, 2007 from http://www.kaimh.org/latino.htm

Mandell, D.S., Listerud, J., Levy, S.E., \& Pinto-Martin, J.A. (2002). Race differences in the age at diagnosis among Medicaid-eligible children with autism. Journal of the American Academy of Child and Adolescent Psychiatry, 41(12), 1447-1454.

Magaña, S., \& Smith, M. (2006). Psychological distress and well-being of Latina and non-Latina white mothers of youth and adults with an autism spectrum disorder: Cultural attitudes toward coresidence status. American Journal of Orthopsychiatry, 76(3), 346-357.

Marshall, K.J., Urrutia-Rojas, X., Soto Mas, F., \& Coggin, C. (2005). Health status and access to health care of documented and undocumented immigrant Latino women. Health Care for Women International, 26, 916-936.

McHatton, P.A., \& Correa, V. (2005). Stigma and discrimination: Perspectives from Mexican and Puerto Rican mothers of children with special needs. Topics in Early Childhood Education, 25(3), 131142.

National Research Council. (2001). Educating children with autism. Washington, D.C.: National Academy Press.

Palmer, R.F., Walker, T., Mandell, D., Bayles, B., and Miller, C. S. (2010). Explaining low rates of autism among Hispanic schoolchildren in Texas. American Journal of Public Health 100(2), 270-272.

Reyes-Blanes, M.E., Correa, V.I., \& Bailey, D.B., Jr. (1999). Perceived needs and support for Puerto Rican mothers of young children with disabilities. Topics in Early Childhood Education, 19(1), 54-63.

Sanchez, L.L. (2006). Barriers to diagnosis and treatment services faced by Latino parents of children with autism: Understanding the needs of Latino families. Unpublished doctoral dissertation. The Chicago School of Professional Psychology.

Shieve, L.A., Blumberg, S.J., Rice, C., Visser, S.N., \& Boyle, C. (2007). The relationship between autism and parenting stress. Pediatrics, 119 (supplement February, 2007), 114-121.

Torres, L., \& Rollock, B. (2004). Acculturative distress among Hispanics: The role of acculturation, coping and intercultural competence. Journal of Multicultural Counseling and Development, 32, 155-167.

United States Department of Education. (2004). Twenty sixth annual report to congress on the implementation of the Individuals with Disabilities Education Act. Retrieved October 17, 2006 from http://www.ed.gov/about/reports/annual/osep/index.html.

\author{
Author Information \\ * Emily Iland \\ California State University, Northridge \\ E-mail: emilyiland@gmail.com \\ Phone: 661.297.4205 \\ Fax: 661.297.4033 \\ Ivor Weiner \\ California State University, Northridge \\ Wendy W. Murawski \\ California State University, Northridge \\ * corresponding author
}

